\title{
CONTRA LA UTOPÍA TEMPORAL: LA TEMPORALIDAD DEL PAISAJE
}

Michael Jakob

Haute École du Paysage, d'Ingénierie et d'Architecture de Genève

\section{RESUMEN}

Ya la primera época de la conciencia del paisaje presentó ambigüedades significativas. Se aspiraba, en efecto, a un ideal -representado por la literatura, la pintura (la Edad de oro) y los jardines (con su intemporal programa de raigambre neoplatónica)-, pero a la vez se iniciaba el proceso de su deconstrucción. De algún modo, en el énfasis en las ruinas y lo efímero, se presentía lo que estaba por llegar. $Y$ es que el paisaje, con su eterno movimiento estacional y su insistencia en lo procesual, nunca pudo instalarse tranquilamente en ninguna utopía total. Desde luego, no resulta extraño que, además de apostar por las estéticas de lo feo y lo fragmentario, el arte contemporáneo del paisaje haya girado siempre en torno al tiempo y la fugacidad.

Palabras clave: arte del paisaje, estéticas de lo fragmentario, historia de los jardines, ruinas, temporalidad

\section{ABSTRACT}

A historical overview of the awareness of landscape reveals that it has been a largely ambiguous field from the very beginning, when the sought-after ideal - embodied by literature, art (the Golden Age), and gardens (with their timeless Neoplatonist-influenced agenda) - was already subject to a process of deconstruction. The period's emphasis on ruins and the ephemeral can be read as a sign of what was to come - landscape, with its eternal movement through the seasons and its insistence on processes, has never settled on a single, all-encompassing utopia. It is not surprising, therefore, that aside from embracing the aesthetics of the ugly and the fragmentary, contemporary landscape art has always centred on time and transience.

Keywords: landscape art, aesthetics of the fragmentary, history of gardens, ruins, temporality

Si existe realmente aquello que se ha dado en llamar «génesis» o «invención» del paisaje, esta tiene, necesariamente, lugar en el tiempo.' Existen, pues, tiempos, épocas, con y sin paisaje. ${ }^{2}$ Las propias épocas del paisaje son entidades temporales: tienen principio y fin, fases de evolución, movimientos ascendentes y descendentes. En otras palabras, el paisaje tiene historia, es la historia de la conciencia del paisaje, y la experiencia del paisaje como experiencia estética vivida no puede existir sino dentro de los límites de dicho marco temporal. El sujeto que construye el paisaje es más que un cuerpo que se desplaza a través del espacio; es también una conciencia imbuida de historia. Allí donde hay paisaje se produce un encuentro entre naturaleza e historia: la historia se inscribe en la naturaleza. 
¿Qué relación existe, entonces, entre la plenitud temporal de la experiencia estética en su singularidad individual y el poso de la historia sedimentada en la conciencia? ¿Acaso son las experiencias individuales vividas a través de un filtro de experiencias colectivas?

En sentido estricto, para convertirse en paisaje, la fracción de naturaleza que nos ocupe no podrá ser determinada a priori. Solo podrá ser descrita y clasificada a posteriori, y solo a la luz de esta caracterización ulterior se revelará como influida por la historia, es decir, por factores temporales. Ahora bien, esto plantea un problema: el de tender un puente entre la subjetividad pura - personal y absoluta - de la experiencia del paisaje y las derivas intersubjetivas y criterios históricos que han ido delimitando el gusto por

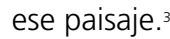

De lo que no cabe duda es de que la experiencia del paisaje aparece marcada por claras diferencias diacrónicas. En efecto, a lo largo de la historia el ser humano ha creado imágenes que han ido cambiando en función de las épocas.

Todo comenzó con la concepción del paisaje bello. En sus inicios, la experiencia del paisaje solo podía tener lugar allí donde la imaginación era capaz de reconocer en la naturaleza formas que evocasen ideas de bienestar, seguridad y armonía. ${ }^{4}$ Sentirse interpelado por esa naturalezajardín implicaba haber interiorizado el proceso cultural de domesticación, el prolongado «trabajo» sobre la naturaleza que precede a toda constitución del paisaje.

No obstante, lejos de derivar hacia cualquier ucrónica utopía, esta primera época de la conciencia del paisaje presentaba ya ambigüedades significativas que después se reflejaron en el plano temporal. Se aspiraba, en efecto, a un ideal representado por la literatura, la pintura (la Edad de oro) y los jardines (con su intemporal programa de raigambre neoplatónica) - al tiempo que se iniciaba ya el proceso de su deconstrucción. Se anunciaba, en cierto modo, lo que estaba por llegar.

\section{Et in Arcadia ego}

La irrupción de la ruina en el paisaje es, bajo esta luz, la primera grieta del ideal que se res- quebraja. Los fragmentos del pasado afloran en el paisaje mucho antes del Renacimiento. Desde los frescos antiguos de Lorenzetti hasta la obra de Giorgione y Mantegna pasando por Patinir - sin olvidar el papel fundamental que desempeñan en el Sueño de Polífilo -, las ruinas están presentes por doquier. La ruina y la muerte habitan el paisaje bello y representan, en su seno, la antítesis misma de lo perenne, la fugacidad de lo terreno. Indicadores de una ausencia, de una falta fundamental, las ruinas hacen añicos los sueños dorados de una naturaleza por siempre pacificada. El paisaje es algo proyectado: construcción subjetiva por parte de un individuo que controla la naturaleza sometida a su mirada. La omnipresencia de las ruinas en el paisaje - que a partir de 1530 convivirán con ruinas artificiales instaladas en los jardines (Pesaro) o con paisajes-ruina como el de Bomarzo - evidencia, no obstante, la revancha de la naturaleza, la inestabilidad y el carácter efímero de la apropiación del mundo. ${ }^{5}$ Por fin, la entrada de la muerte en la Arcadia será la confirmación última de la fragilidad y la futilidad del sueño de la Edad de oro. Los cuadros de Guercino y de Poussin - (Et in Arcadia ego) (Fig. 1) - expresan con increíble fuerza esta diferencia temporal, la separación abismal entre la naturaleza paradisíaca y el ente finito ante la alegoría de la calavera o del sepulcro. ${ }^{6}$ Así confrontada con la finitud, la propia razón de ser de los grandes jardines del Renacimiento y del Barroco se tambaleaba.

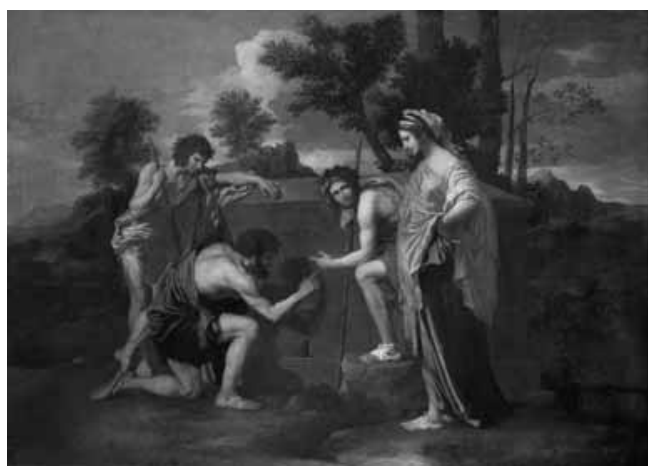

Fig. 1. Nicolas Poussin: Et in Arcadia ego, 1637-1639

A partir de entonces, las fiestas en las grandes propiedades cobran una importancia particular. Así, la otra historia del paisaje bello está 
ligada a los despliegues de lo efímero: es la historia de los espectáculos principescos que, tras proliferar en Italia, se extendieron después a Francia y, por fin, al resto de Europa. Las celebraciones de Ferrara y Milán, los festejos toscanos (cuyo efecto secundario será el nacimiento de la ópera), el gran día funesto de Vaux-le-Vicomte o los Plaisirs de l'île enchantée de Versalles son algunos de los ejemplos que conforman todo un abanico de momentos paisajísticos ejemplares a la par que fugaces.

La primera época de la naturaleza bella o naturaleza-jardín de simetrías formales llega a su fin con la revolucionaria aparición en escena del jardín pintoresco (o irregular, a la inglesa, anglochino:). La lógica temporal de estas nuevas realizaciones $-y$, de forma similar, de la lectura de los paisajes en general - es totalmente distinta. Todas estas propiedades ajardinadas tienen en cuenta el tiempo individual del paseante, del caminante melancólico que deberá «perderse» en meandros y caminos que se bifurcan. El sujeto no es ya aquel subalterno pasivo sometido a una estructura absolutista que fija, de una vez por todas, la posición que todo y todos deben ocupar. Ahora, con su caminar, compone su propio paisaje y, con ello, se compone a sí mismo. El conocimiento-construcción del jardín pasa a ser un acontecimiento singular, una fecha individual. Es entonces cuando la ruina, memento mori y metonimia de la antigüedad en los jardines de otrora, y, sobre todo, la falsa ruina pasan a ocupar el centro de las composiciones paisajísticas. Así, enmarcados en un dispositivo semiótico de gran complejidad, la Columna del Desierto de Retz o el Templo de la Filosofía de Ermenonville hacen las veces de faros, de símbolos arquitectónicos de la diferencia temporal.

En todos y cada uno de los elementos que conforman estas composiciones paisajísticas es ostensible la impronta de la discontinuidad: el paseante se detiene en ermitas y otros «desiertos» solemnes, interrumpe su trayecto y medita acerca de la falsa grandeza de las civilizaciones, de la historia, de la continuidad, del programa. Todo se fragmenta y la melancolía se instala, el futuro mismo parece resquebrajarse - algo que anticipara con maestría uno de los protagonistas de la nueva estética pintoresca, Hubert Robert, con su visión del Louvre en ruinas (Fig. 2). En efecto, las grandes propiedades morirán con la Revolución convertidas ruinas de sus contradictorias aspiraciones.

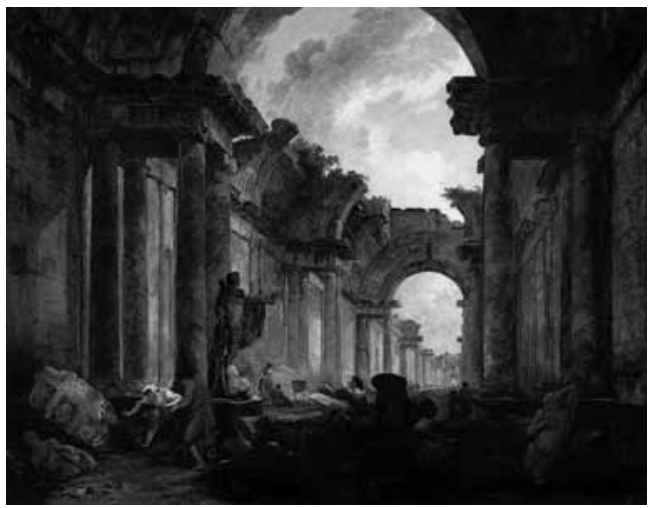

Fig. 2. Hubert Robert: Vista imaginaria de la Gran Galería del Louvre en ruinas, 1796

Ahora bien, antes de la ruptura producida por la Gran Revolución -es decir, en el periodo en que la visita a estas fincas era segura y cumplía funciones pedagógicas- lograría sobrevivir un elemento estático de la contemplación, pues - como hace constar el marqués de Girardin en su teoría De la composition des paysages (1777) -, con frecuencia se esperaba que los paseantes reconocieran los modelos pictóricos trasladados al terreno por el flamante jardinero-paisajista. ${ }^{9}$ La auténtica labor de creación y construcción es, pues, desplazada al interior del sujeto, allí donde el recuerdo y la imaginación han de dar continuación a aquello que en un determinado momento no era sino mero impulso. Lo que, a fin de cuentas, percibía quien contemplaba este tipo de parques, no era tanto la naturaleza reconocida o considerada como tal, sino más bien la propia historia de sí mismo, esto es, su devenir individual marcado por la historia. Como resultado, el propio concepto de finitud se diluye en la infinitud de una interioridad magnificada:

Si el jardín pintoresco -que tal vez sería más acertado llamar jardín de la sensibilidad- ha sido tan amigo de las ruinas y las tumbas, es porque estas se revelaban a los ojos del paseante como una imagen de la vida misma del pensamiento humano. Ponían a disposición de las almas sensibles el dolor de percibirlas y la consolación de contem- 
plar cómo la naturaleza conservaba en ellas una imagen de nuestro pensamiento. Dolor aplacado capaz de suscitar placer, inducían en el paseante un estado inestable y delicioso en el que sus estados de ánimo podían modularse sin cesar hasta transformarse en su opuesto. ${ }^{10}$

\section{Más allá de lo bello}

Al gran período histórico de la naturaleza bella, pintoresca y sublime, fuente de la experiencia del paisaje, sucede la época que podríamos definir como del «paisaje más allá de lo bello», la cual se extiende hasta nuestros días. Lo feo, lo fragmentario, lo imperfecto y hasta lo desagradable pasan a formar parte del campo visual, y a su lado brotan otras formas de temporalidad. En torno a los años 1860-70, el gusto por lo «no-bello» se convierte en un fenómeno de influencia notable: "J'adore la banlieue avec ses champs en friche/Et ses vieux murs lépreux, ou quelque ancienne affiche/Me parle de quartiers dès longtemps démolis» («Me cautiva el suburbio con sus campos yermos/Sus paredes leprosas, en que algún cartel viejo/Me habla de barrios ha tiempo demolidos»), escribía François Coppée en su Promenades et Intérieurs."

Son muchos los puntos de contacto que emparentan la arquitectura del paisaje contemporánea con este imaginario de lo "no bello», aquel de la ciudad herida y asfaltada, de la città diffusa, de la no man's land, de los slums, de los descampados -eriales agrícolas, industriales o urbanos- y de los vertederos. Esta sorprendente centralidad de los márgenes, de la periferia, es el resultado de una tendencia que se extiende a lo largo de varias décadas y cuyos orígenes se remontan, entre otros ámbitos, al land art y a los proyectos fotográficos de los new topographers (a la exposición New Topographics que tuvo lugar en Nueva York en 1975), pero que parte también de la estética cinematográfica - de Antonioni, de Tarkovski (Fig. 3).

La belleza extraña de este nuevo paisaje tecnológico marcado por los cuatro costados por la intervención humana nos enfrenta a situaciones contradictorias. Es este un paisaje del vacío $y$, al mismo tiempo, de lo demasiado lleno, de la ausencia y de la saturación. Es tan fascinante como angustioso, rayano en lo repugnante, y culmina en distintas combinaciones que rozan el estado de podredumbre. ${ }^{12}$ Se trata de un paisaje sin límites definidos, difuso, que por todas partes exhibe los estigmas de la no asimilación de los elementos que lo componen, las huellas melancólicas de lo inacabado.

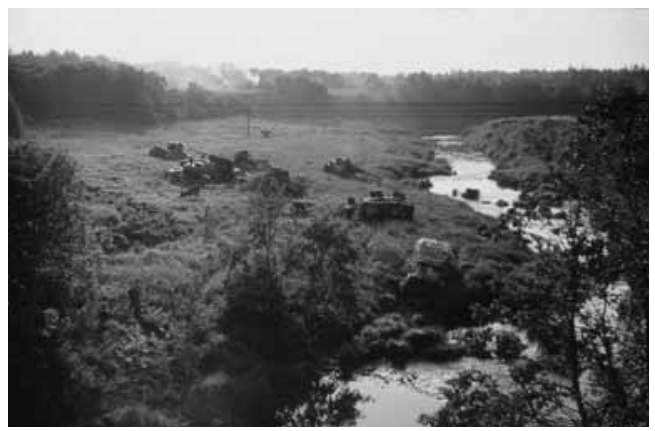

Fig. 3. Andrei Tarkovsky: Fotograma de Stalker, 1979

A finales del siglo $X X$, la arquitectura del paisaje se orienta de forma manifiesta hacia este paisaje otro situado más allá de las estéticas de lo pintoresco. Como bien explica Dieter Kienast:

Nuestra tarea consiste en la búsqueda de una naturaleza de ciudad en la que el color presente no sea únicamente el verde, sino también el gris. Naturaleza de ciudad es sinónimo de árbol, de seto, de césped, pero también de pavimento que permite el paso del agua, de espacio amplio, canal riguroso, muro elevado, eje de aire fresco o de vista ininterrumpida, de centro y de margen. Dedicamos especial atención a los incontables nolugares nacidos de la planificación y la ordenación burocráticas. Las acciones urbanísticas, entre las que incluimos la arquitectura del paisaje, son, a nuestro juicio, de vital importancia especialmente para la periferia, para los residuos de espacio indeseados de la metrópoli. ${ }^{13}$

A pesar de este creciente interés por la periferia, la naturaleza residual y la antinaturaleza, la naturaleza pura - o, mejor dicho, el simulacro de una naturaleza «pura» o "verdadera» - sigue conservando su estatus y pervive especialmente en su faceta museística. Es reclamada y elogiada por el público contemporáneo, y es la naturaleza de las vacaciones y el ocio, la naturaleza cercana y lejana, la de las playas, las cumbres alpinas y los desiertos, es decir, la naturaleza reproducida hasta la saciedad, todas y cada una de cuyas piezas han sido fabricadas por el discurso paisajístico 
global. Entretanto, la arquitectura contemporánea de vanguardia, que parece haber dejado atrás la estética de los jardines y el culto a la naturaleza bella, toma un camino radicalmente distinto y privilegia, en su lugar, todo lo que se inclina hacia lo urbano, incluso hacia lo hiperurbano.

Hoy la arquitectura del paisaje incluye en sus proyectos los ambiguos signos de nuestra época, a saber, el sentido de la dispersión y la fragmentariedad. ${ }^{14}$ Así las cosas, ¿qué caracteriza el estilo de alguien como Dieter Kienast, sino la voluntad de imponer resueltamente, obstinadamente, un gesto arquitectónico antitético, perturbador? La extrema austeridad de los medios utilizados y su característica puesta en escena (al estilo Gestalt) de los elementos formales distinguen sus obras del habitual modelo anodino repetido hasta la saciedad. De este modo, Kienast rompe tanto con la tradición idílica o romántica como con las prácticas de ordenación de los jardines que dan prioridad a la variedad y la exuberancia de las plantas (la fiebre del coleccionismo). La marcada oposición entre la enérgica presencia de lo vegetal y la disciplina formal de las geometrías inventadas, sumada a la creación de una espacialidad que se sale de la norma (sin caer en el uso de gags en corten $u$ otras provocaciones baratas) demanda una interpretación activa del lugar por parte del que penetra estos espacios; reclama una vez más el tiempo del descubrimiento (Fig. 4).

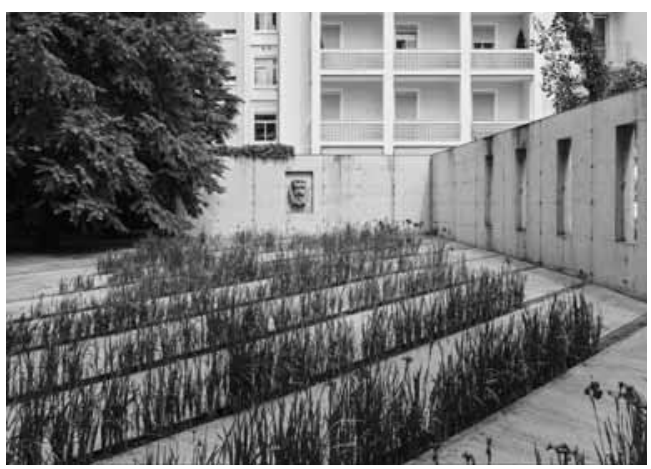

Fig. 4. Dieter Kienast: Jardín de Swiss Re, Zurich, 1995

Otros, como Gilles Clément, tratan de reintegrar sus composiciones en la naturaleza y otorga la soberanía al tiempo que le es propio. En la obra de Clément, la firme negación del orden inamovible en favor del desorden creativo parte de la convicción de que, como habitante de la Tierra, el ser humano ve cómo el tiempo se escapa entre sus dedos. La perspectiva ecológica defendida por el teórico del «jardín planetario» redunda en la exposición de la obra a los azares y accidentes de la naturaleza. Mientras que el arte de los jardines tradicional aspiraba a la dominación del tiempo - de forma especialmente notoria en los jardines racionalistas de tipo francés con su control total del crecimiento, de la forma, del cromatismo, de las estaciones, etc. Clément devuelve la naturaleza a la naturaleza (Fig. 5). La libertad imprevista de sus proyectos se inspira tanto en los «jardines involuntarios» descubiertos en descampados de todo el mundo como en el espectáculo del brassage o mestizaje de las especies (sobre todo de las errantes) que da lugar a nuevos paisajes. Esta libertad reencontrada nos invita a participar del tiempo a través del encuentro constante con elementos inesperados, de la estética del décalage o desajuste cultivada por el botánico:

Los desajustes son fenómenos menores a la par que esenciales. Funcionan como catalizadores, desencadenan reacciones imprevistas, introducen en el paisaje dimensiones singulares fuera del contexto en el que surgieron, dimensiones que a veces son íntimas por el hecho de ser subjetivas. Lo interesante de los desajustes es su capacidad de reactivar la dinámica de la observación. ${ }^{15}$

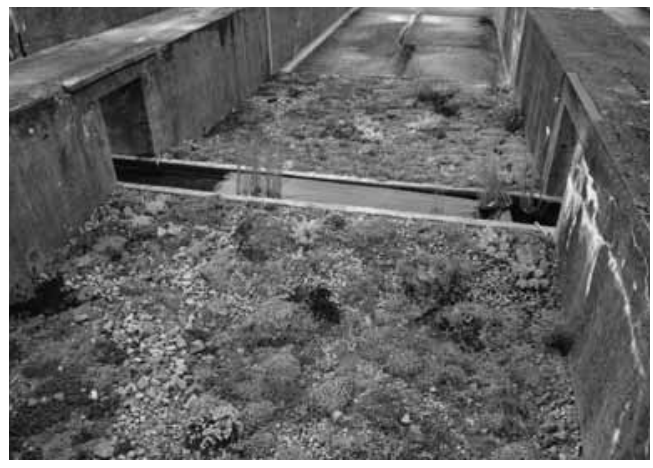

Fig. 5. Gilles Clément: Jardín del Tercer paisaje sobre base submarina alemana, St-Nazaire, Loira, 2009-2011

Concebidas como prácticas que reconocen la importancia del tiempo, es posible establecer una conexión entre esta estética de Gilles Clé- 
ment y alguna obra de Derek Jarman. El jardín del artista inglés, situado en Dungeness, en la costa de Kent, es una obra «terminal». Acechado por una muerte inminente, Jarman inventa un espacio de libertad en un entorno austero y extraño. El propio proceso de creación que da lugar a este antijardín enuncia la cuestión del tiempo: ¿para quién - durante cuánto tiempo en cuánto tiempo se adecenta un lugar? ¿Y qué será de él cuando llegue la muerte, esa muerte que es la huésped indeseada de la historia de los jardines, la muerte de Julie y de su Elíseo en la obra de Rousseau, la muerte de Charlotte y de Otto en las Afinidades electivas, o, más concretamente, la muerte de los parques y de los paraísos paisajísticos en la época de la Revolución, de la que da cuenta, entre otros, Sylvie de Nerval?16 Vivir y extinguirse en su jardín es, sin embargo, el destino final del príncipe Pückler, encerrado para siempre jamás en su pirámide, auténtico monumento de su ser en el momento mismo de su desaparición. ${ }^{17}$ El jardín de Dungeness está marcado por la finitud, la mortalidad de la existencia humana, una situación que es, sin embargo, liberadora para su autor, para quien este espacio se convierte en un último remedio poderoso y terapéutico (en la tradición del jardín medicinal).

La despedida paisajística de Jarman ha demostrado ser, a pesar de su espontaneidad y aparente simplicidad, una obra de extraordinaria complejidad. El cottage, con su vegetación espontánea y sus objetos encontrados, funciona como una "gran propiedad» de la memoria cultural. Los trozos de madera y otros fragmentos verticales clavados en la tierra nos recuerdan el acto primordial del dominio del territorio, la estaca que marcaba el terreno o la piedra miliaria. En esta waste land la antropología del homo erectus adquiere matices particulares en dos aspectos: uno lleno de energía, aquel de la proyección hacia el cielo, de la vertical victoriosa; otro melancólico y friedrichiano, el de una elevación a tiempo pero de alcance limitado (Fig.6).

En los aledaños más inmediatos de una central nuclear - con todo lo que implican tanto su contexto real como los imaginarios a ella asociados el jardín seco y mineral toma la forma de un gesto final y desesperado, comparable al Monje a la orilla del mar de Caspar David Friedrich. La amplitud

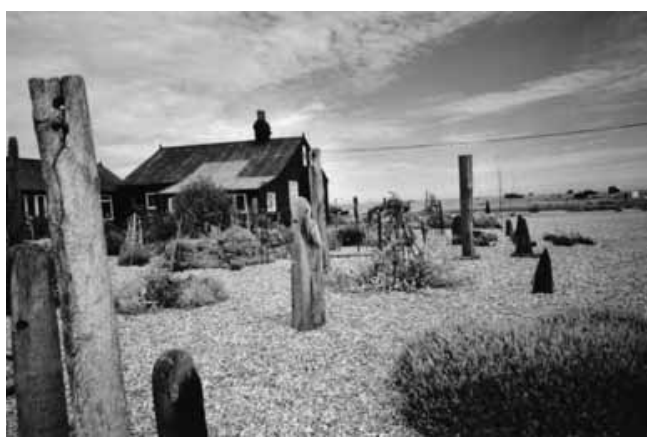

Fig. 6. Derek Jarman: Jardín de Dungeness, Kent, 1993

del inmenso cielo y el juego y la resistencia inauditos de la vegetación representan, sin embargo, en este desorden poético, la propia fuerza de la vida. También la belleza efímera de las amapolas que se destaca sobre los níveos fondos del seco plantío de impronta oriental es una expresión de vida, de las complejas y múltiples caducidades de lo vivo. Con su última obra, Jarman crea un espacio colmado de guiños más o menos involuntarios: el concepto de ready made, la técnica de collage y ensamblaje de Schwitters, la poesía de las máquinas de Tinguely, los objetos de piedra de Richard Long, o incluso las creaciones de Yves Tanguy aparecen singularmente reflejados en la obra de Jarman. Todo en Dungeness tiene su sentido, aunque este no es explicado, de forma que el visitante se ve obligado a agudizar su atención ${ }^{18}$. Con este jardín de la desintegración y de la desaparición, en el que hasta el óxido desborda vigor, Jarman fue capaz de resucitar una realidad de antaño, y, con ella, un poderoso dispositivo paisajístico del pasado: aquel del jardín pintoresco (o inglés) que, en su calidad de objeto artístico concebido para ser percibido por un paseante sensible, provocaba el despertar del sujeto y, sobre todo, la toma de conciencia de una temporalidad que siempre apelaba al núcleo de la propia subjetividad.

De hecho, se tome el ejemplo de Kienast, de Clément o de Jarman, todas estas obras tienen en común la fragmentariedad y la aceptación de los efectos del tiempo.

\section{Autopia}

Si hoy en día el arquitecto del paisaje apuesta por integrar en sus proyectos la diferencia temporal, la industria de la imagen (de la publi- 
cidad, del viaje), por su parte, se aferra al tiempo nivelado. Su ideal es la pervivencia de un paisaje de tarjeta postal que gusta porque ofrece un espectáculo ucrónico, eterno. ${ }^{19}$ Si se observan detenidamente, estos paisajes, además de ser notablemente antropomorfos, demuestran estar ligados a la imagen glorificada de la explotación agrícola. El paisaje modelado por la agricultura se convierte en paisaje ideal en aquellos lugares en que esta es observada desde fuera (por el turista), donde se encuentra en crisis (la prolongada muerte del campesinado enfrentado a la mecanización), o bien allí donde, ya superada históricamente, se adorna de añoranzas de la tierra natal. Este paisaje refleja entonces el bon vieux temps, the good time ${ }^{20}$, un tiempo que, sin embargo, jamás existió realmente. ${ }^{21}$

Frente a la muerte de la ruralidad preindustrial, el culto de lo rural y de lo arcaico sustituye la reflexión, el enfrentamiento con el cuerpo agonizante de la agricultura. Este tipo de sacralización conduce, necesariamente, a soluciones dudosas, como la de erigir a los últimos campesinos en "guardianes del paisaje».22 La simultaneidad de estas dos estéticas deriva en una polarización cercana a la esquizofrenia: hoy adoptamos el papel del espectador o ciudadano ávido de naturaleza - aquel que opina que todo debe seguir siendo exactamente como era, que es necesario detener oficialmente la urbanización - y, al mismo tiempo, participamos de buena gana en la fugacidad frenética de la modernidad posindustrial. Defendemos la protección de los iconos paisajísticos, congelados y en vitrina, sin por ello dejar de espolear las fuerzas que, con su impronta, marcaron no solo los sueños (y las pesadillas) futuristas, sino también el siglo XX en su totalidad, a saber: las fuerzas de la velocidad.

John Brinckerhoff Jackson fue uno de los primeros en señalar las repercusiones de la perspectiva automovilística sobre la vida y el paisaje contemporáneos. Jackson habla de la

propagación de un nuevo tipo de paisaje, basado no tanto en la territorialidad y en los espacios característicos de acceso limitado, sino, cada vez más, en el gusto vernáculo por la movilidad y en el uso temporal de espacios públicos o semipúblicos [...] Una de sus características era la accesibilidad, la otra el nuevo estilo del que hacía gala el exterior de los edificios: alegre, no convencional y clara- mente concebido para atraer al consumidor móvil obligándolo a detenerse. El strip es uno de los ejemplos más tempranos de arquitectura ideada para ser experimentada desde fuera, y que puede ser aprehendida por el conductor que pasa por su lado. He aquí el origen de invenciones como el drive-in bank, el cine drive-in, o incluso la iglesia drive-in. Vieron también la luz el aparcamiento gigante para camioneros, el supermotel, el supermercado, y hasta el supertaller a disposición de los automovilistas; un paisaje fabricado a medida que albergaba todos los servicios comerciales relacionados con el automóvil: cambio de neumáticos, pintura de la carrocería o venta de coches. ${ }^{23}$

Podemos contrastar la neutralidad de esta descripción de un paisaje marcado por el tráfico y el tiempo acelerado con las polémicas palabras de lan McHarg en el siguiente extracto de su Design with Nature:

¿Cuáles son las pruebas evidentes del credo mercantil estadounidense? El puesto de hamburguesas, la gasolinera, el restaurante de carretera, los omnipresentes paneles publicitarios, el cableado eléctrico hecho colgajos, las zonas de aparcamiento, los desguaces y esa simbiosis total entre la rapacidad territorial y la desilusión humana que son los complejos de viviendas. Fuera de los confines de la ciudad, es absolutamente imposible escapar a las autopistas, pues es alli donde nos espera, en todo su esplendor, la quintaesencia de la vulgaridad, concebida para atribuir la máxima importancia a la más insignificante de nuestras creaciones. ${ }^{24}$

Pero no sucede solo en Estados Unidos. En todo el mundo, las infraestructuras ligadas a los medios de transporte son las auténticas arterias de un sistema que invade la totalidad del territorio. El paisaje urbano, las carreteras para salir de la ciudad, los pueblos que ya no son tales, los lugares de vacaciones entendidos como simulacros de la forma urbana han sido concebidos para el conductor que los aprehende mientras circula. Tras la segunda guerra mundial - si no antes -, se hace patente la victoria de la «autopía» (R. Banham), que se impone en los ámbitos cultural, social y económico.

Durante mucho tiempo, modernidad fue sinónimo de automovilidad. «El sentir espaciotemporal de nuestra época se experimenta mejor conduciendo un vehículo, cuando las manos reposan sobre el volante mientras atravesamos 
valles y montes y enfilamos viaductos sobre rampas y puentes gigantescos». ${ }^{25}$ El automóvil no solo dio lugar a nuevas formas paisajísticas (streetscapes), sino que también generó otro modo de aprehender la realidad26:

La panorámica de las carreteras es la prueba de la magia a través de la cual el paisaje se impone a la persona y la desborda. Se experimenta, simultáneamente, una desconexión del marco espacial inmediato y una sensación de proximidad visual que es casi un aplastamiento, término que aquí hace referencia a la supresión de la profundidad de campo por parte de la fotografía y el cine. El sujeto ve cómo el espacio se despliega ante él, lo recibe, adopta un papel de puro espectador. ${ }^{27}$

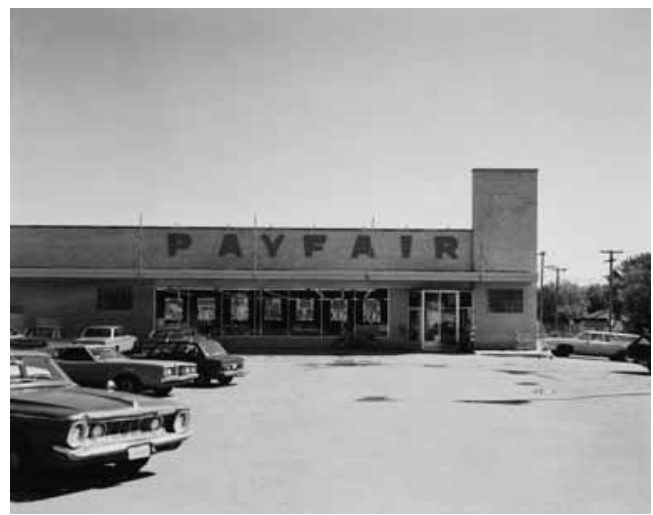

Fig. 7. Stephen Shore: Winnipeg, Manitoba, 1974

El automóvil perpetúa las contradicciones de la movilidad (una característica fundamental de la modernidad): genera nuevas topografías y nuevas posibilidades estéticas para la exploración de la realidad (Fig. 7), pero, al mismo tiempo, destruye el encanto de esa misma realidad hacia la que facilita el acceso:

La cultura del automóvil contribuye a la destrucción del medio natural y del paisaje rural. El turismo automovilístico fomenta la construcción de moteles, gasolineras, miradores y todo tipo de establecimientos para el ocio que prolongan y desintegran los antaño bien definidos ángulos urbanos. Lugares como el de los cañones rojos de Sedona en Arizona son destruidos por el progreso y la panorámica de los acantilados escalonados es interrumpida por paneles publicitarios de Happy Meals. [...] de forma más insidiosa si cabe, los complejos de viviendas que circundan la mayor parte de las ciudades estadounidenses, con su uniformidad y sus extensas planicies de colores, se erigen frente al conductor como un equivalente arquitectónico de los grandes espacios salvajes -carecen de puntos de referencia que permitan comprender la geografía del lugar y su contexto estético. Monótonos campos de maíz suceden a campos de tejados grises. Colinas de maquis se alternan con colinas de tejados rojos. Con cada curva, con cada nuevo kilómetro, se reanuda el padecimiento de la monotonía y de la homogeneidad. Conductor y pasajero se hunden sin remedio en el mar suburbano. ${ }^{28}$

\section{Time Landscape}

Desde un punto de vista temporal, el ideal autópico que modeló los paisajes de posguerra tiene como guía el avance inexorable, la proyección hacia el futuro, puesto que nunca miramos atrás, sino al frente, siempre hacia adelante. Sin embargo, conforme ha ido creciendo la esfera autópica, el número de espacios alcanzables se ha ido reduciendo. En el imaginario territorial esto ha dado lugar a la paradójica convivencia del sprawl urbano, la génesis a gran velocidad de espacios intersticiales ilimitados gobernados por la tecnología, la omnipresencia de las máquinas y la supervivencia de retazos de naturaleza hurtados al progreso que toman la forma de enclaves residuales.

La tendencia actual de la arquitectura y del urbanismo, pero también de las humanidades y de la cultura en general, de orientarse con determinación hacia la periferia, hacia los lugares intersticiales y las metástasis territoriales constituye un fenómeno paisajístico notable, con relación al cual el tiempo se presenta de nuevo como un factor especialmente pertinente. Campos en barbecho, enfermizos distritos industriales, arrabales lúgubres y tierras de nadie contaminadas son hoy objetos de fascinación. Si en el pasado la fotografía de moda elegía como escenarios palacios, villas, cumbres montañosas o playas exóticas, hoy es frecuente que las modelos se vean obligadas a exhibir sus costosos atuendos en vertederos o fábricas abandonadas, en medio de paisajes híbridos que se oponen a la estética de lo bello. El cine y la publicidad han contribuido a reforzar aún más esta tendencia, y muy pronto, si es que no ha sucedido ya, la industria del turismo ofertará visitas organizadas a las barriadas de chabolas, viajes al extrarradio de 
Beirut, de Sarajevo o de Bagdad, establecimientos bed and breakfast que ofrezcan algo distinto. ${ }^{29}$ Esta tendencia a buscar, incluso a celebrar lo feo, lo híbrido y lo periférico es también el fruto del fracaso del progreso, o bien de la pérdida de fe en él. Pareciera, en efecto, que «la contradicción, en su propia evolución, hubiera [hecho despertar] a la mente y que intenta, si bien en vano, sacarla de su error recurriendo a aquello de lo que esta se había distanciado, motivo por el cual lo cree, erróneamente, inmutable». ${ }^{30} \mathrm{El}$ impulso orientado hacia el futuro, hacia adelante - el paisaje como horizonte y apertura: "El horizonte abierto de la experiencia del espacio demanda un horizonte de la historia abierto sobre el futuro, es decir, un horizonte que permita al hombre modelar libremente ${ }^{131}$ - deja entonces paso a escenarios entrópicos, algo que ya había sacado a relucir Robert Smithson en los años 60 cuando dirigió su atención al paisaje contaminado, destruido, amenazado.

En sus obras, el vector del futuro, que aparecía ya desestabilizado en las representaciones estáticas de Caspar David Friedrich, se halla totalmente invertido. La evolución -la espiral- gira en sentido contrario, hacia atrás (Spiral Hill, Emmen), el tiempo se encoge, desaparece inexorablemente, al igual que la Spiral Jetty (1970), símbolo de una época dominada por la entropía - en la obra de Smithson, el «retorno a la naturaleza» está ligado a una estética de la desaparición (Fig. 8). El modo en que este trabajo del artista estadounidense actúa tanto sobre nuestra conciencia del tiempo y de la historia en general como sobre la estética retrógrada del paisaje aparece reflejado en un cuadro honda-

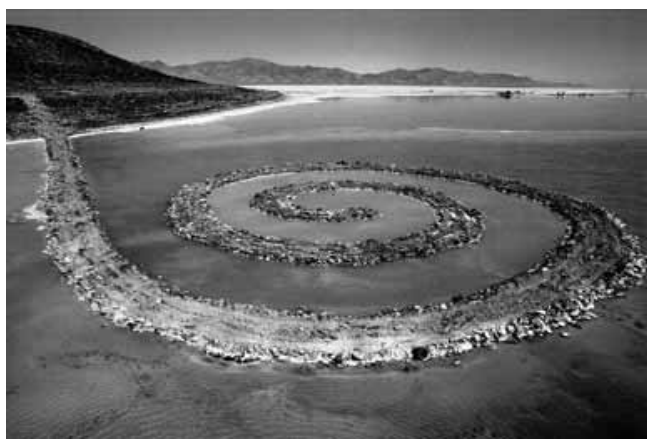

Fig. 8. Robert Smithson, Spiral Jetty, Great Salt Lake, Utah, 1970 mente irónico de Mark Tansey (Purity Test, 1982) en el que un grupo de indios a caballo parece arrojar una última mirada perpleja a la Spiral Jetty, producto final de la conciencia europea del paisaje que, al mismo tiempo, la niega. Esta contradictoria representación deconstruye los grandes mitos históricos (los discursos de épocas de transición, de cambios de paradigma, etc.) y saca a la luz sus contradicciones desde un punto de vista que, como constructo cultural que es, sigue evidenciando ambigüedades temporales. Los artistas hoy considerados pertenecientes a la corriente del Land Art siempre han dado prioridad al fenómeno del tiempo. Time Line y Time Pocket (1968) de Dennis Oppenheim exploran las líneas internacionales del tiempo por medio de movimientos que dejan una huella efímera (las marcas de veinticinco centímetros de ancho de la motonieve) en lo efímero (el río Saint John, helado y cubierto de nieve). El tiempo abstracto, reglado, se "vuelve loco" y la convención temporal (las zonas horarias) es abolida, pero, como suele ser común a este tipo de obras, la acción del artista no deja más huella que un rastro fotográfico.

Annual Rings (1968), también de Oppenheim, tiende un puente entre la medida temporal de la naturaleza (los anillos de los árboles) y el tiempo medible y racionalizado, que se escinde de forma chocante en la frontera horaria entre Canadá y los Estados Unidos (Estados Unidos 13:30 h - Canadá 14:30 h). Como Smithson y Richard Long, Oppenheim coloca el proceso artístico frente a las convenciones temporales y frente al momento de la recepción de las obras de arte (Fig. 9). El instante, la acción significa-

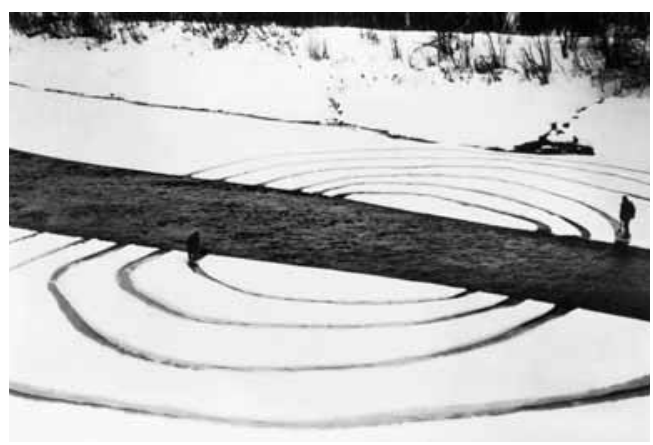

Fig. 9. Dennis Oppenheim: Annual Rings, Fort Kent, Maine, 1968 
tiva, limitada en el tiempo, la actualidad... son así contrapuestas a la eternidad del arte, al lugar que le ha sido asignado en las salas de los museos con sus inmóviles monumentos. La conciencia del paso del tiempo no solo no es repudiada, sino que constituye, además, la materia prima de obras como Spiral Jetty y One Hour Run de Oppenheim (1968) o A Walk of four hours and four circles de Richard Long (1972).

Otra obra de la misma época insiste también en la complejidad de la experiencia temporal. Time Landscape (1978) de Alan Sonfist reconstruye en Manhattan, en plena selva «urbana» y al lado mismo de la «selva» de rascacielos, la selva virgen biológica anterior a la llegada del ser humano a la península neoyorquina. La «ventana» espaciotemporal de Sonfist arroja luz tanto sobre el pasado lejano, preantropomorfo, como sobre un futuro en el cual Manhattan, monumento de la civilización por excelencia, podría ceder de nuevo al bosque primitivo el espacio que le fuera arrebatado.

También el cine estructural de los años 70 plantea la cuestión del tiempo en la experiencia del paisaje. En Seven Days de Chris Welsby -el título es ya una clara alusión a una unidad de medida importante en nuestro sistema de medición del tiempo y a las connotaciones culturales del número siete- los siete días de doblaje se encuentran condensados en diecinueve minutos, en los que cada plano deja paso al siguiente cada diez segundos. El hecho de que la cámara capte la acción en las horas diurnas otorga a la película una duración y una banda temporal que cobran relevancia al ser observados desde una perspectiva antropológica y territorial (Fig. 10).
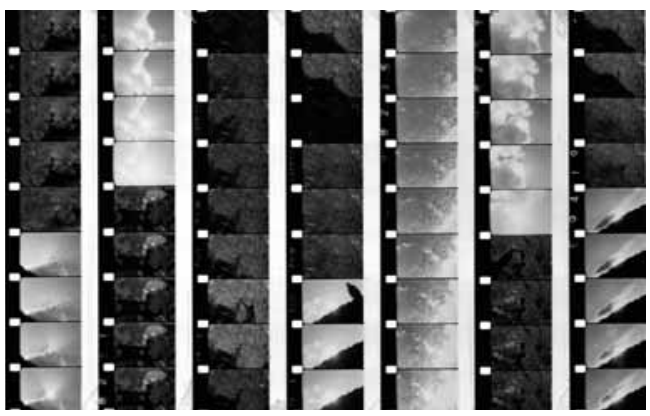

Fig. 10. Chris Welsby: Diferentes fotogramas de Seven Days, 1974

La mirada tecnomorfa de Welsby nos recuerda el punto de vista humano, pero también la práctica milenaria de observar los cielos. En esta obra es precisamente el movimiento maquinal y rítmico de la cámara el que hace aflorar aquello que hay de humano en la construcción de lo visible, junto con todo lo que, bien porque se encuentra circunscrito al ámbito de la naturaleza, bien porque es, en sí mismo, un elemento natural, escapa al hombre:

Dos imágenes que comparten el mismo encuadre nunca son estrictamente idénticas, sino que entre ellas existen infinidad de diferencias. Cambia la forma de las nubes, su transparencia, sus colores. Cambian los colores del cielo, la luz que se proyecta sobre el paisaje, la superficie del paisaje. ${ }^{32}$

Como ese paisaje se ha encargado de recordarnos una y otra vez a lo largo de la historia, nunca dos imágenes pueden ser idénticas porque, lejos de captar la luz de un espacio abstracto o de laboratorio, son fruto de un mundo real en el que el tiempo fluye sin parar. De hecho, visto lo visto, hasta podría decirse que el arte del paisaje nunca nos ha enseñado otra cosa. 


\section{NOTAS}

${ }^{1}$ Este artículo, editado y adaptado por Federico L. Silvestre, recoge algunas ideas presentadas en el libro Paysage et temps (Lausanne 2007) inéditas en lengua castellana. Las páginas reunidas han podido verterse al castellano gracias al desinteresado esfuerzo de Cristina R. Lesmes.

2 «Distintos autores -de forma, a mi juicio, un tanto superficial- han afirmado que el auténtico "sentir de la naturaleza" se desarrolló, en realidad, durante la modernidad, y han atribuido su despertar al lirismo, el romanticismo y demás característicos de estos tiempos. Las religiones primitivas dejan entrever, a mi modo de ver, un sentir de la naturaleza particularmente profundo. Es la sensibilidad ante el "paisaje" como objeto la que surge de forma tardía, y esto es así precisamente porque para posibilitar su creación era necesario rechazar el sentir único y homogéneo asociado a una naturaleza universal» (Georg Simmel, Philosophie der Landschaft, en: Aufsätze und Abhandlungen 1909-1918, vol. 1, Francfort sur le Main 2002, pp. 471-482: 472-3 [existe traducción al castellano, incluida en El individuo y la libertad, Barcelona, Península, 2001]). Cf. también Michael Jakob, L'émergence du paysage, Lausanne 2004; Piero Camporesi, Le belle contrade, Milano 1992. W. J. T. Mitchell (Landscape and power, Chicago 2002) ha calificado esta cronología de la evolución del paisaje de «pseudohistorical myth» y ha señalado su ambivalencia: «lt is almost as if there is something built into the grammar and logic of the landscape concept that requires the elaboration of a pseudohistory, complete with a prehistory, an originating moment that issues in progressive historical development and (often) a final decline and fall» (p. 12). Su apreciación, no obstante, no pasa de ser una mera crítica de las «Western ideas» o la «Western mind» (p. 13), y no propone alternativa alguna. Una historia del paisaje, aunque sea otra historia del paisaje -de «woman, gatherer, scientist, poet, interpreter, or tourist» (p. 16) está también determinada por factores históricos.

${ }^{3}$ Cf. Michael Jakob, L'émergence, op. cit.
${ }^{4}$ Cf. Jay Appleton, The experience of landscape, Londres 1975.

${ }^{5}$ Cf. Thomas M. Greene, The Light in Troy: Imitation and Discovery in Renaissance Poetry, New Haven 1982; Hartmut Böhme, Ruinen - Landschaften. Zum Verhältnis von Naturgeschichte und Allegorie in den späten Filmen von Andrej Tarkowskij, en: Natur und Subjekt, Francfort sur le Main 1988, pp. 334-379.

${ }^{6}$ El primer paisaje designado con este nombre, La Tempesta de Giorgione y las ruinas. También las ruinas en la obra de Patinir

${ }^{7} \mathrm{Cf}$. acerca de lo efímero y el jardín barroco Michael Jakob, Cos'è barocco nel giardino barocco ?, en: Horti Verbani. Coltura e cultura dei giardini verbanesi, Verbania 2001, pp. 97-109; Michel Baridon, Les Jardins de l'âge baroque et le style de Le Nôtre, en: Les Jardins à la française de la Renaissance à nos jours, Les Dossiers de l'Art, n 89, pp. 28-51.

${ }^{8} \mathrm{Cf}$. John Dixon Hunt, The picturesque garden in Europe, Londres 2002.

${ }^{9}$ «El objetivo fundamental es, entonces, comenzar bien por componer el gran repertorio y los cuadros para la estancia por todos los lados hacia donde se dirigen las vistas principales [...] para componer un paisaje y trasladarlo al terreno, el cuadro es lo único que nos puede ayudar a tener una visión clara del resultado antes de ejecutar el proyecto» René-Louis de Girardin, De la composition des paysages, Seyssel 1992, pp. 23, 29. Cf. el capítulo. VIII en su totalidad, pp. 67-68. Como ya afirmara Pope: «All gardening is landscape-painting. Just like a landscape hung up» (citado en John Dixon Hunt (ver nota 33), pp. 14-5 (entre otras apreciaciones acerca del papel que desempeñan los cuadros).

10 Michel Baridon, Les mots, les images et la mémoire des jardins, en: Le Jardin, art et lieu de mémoire (ed.: M. Mosser, Ph. Nys), Besançon 1995, pp. 183-206.

11 François Coppée, Fuvres complètes: Poésies, tome I, Paris 1885, p. 317.

12 «We have gone from ruin to rust, from trace to waste.» (Antoine Picon, Anxious Landscapes From the Ruin to Rust, en: Grey Room 01, Fall 2000, p. 77).
13 Dieter Kienast, Die Poetik des Gartens. Über Chaos und Ordnung in der Landschaftsarchitektur, Bâle 2002, pp. 207-8.

${ }^{14}$ A propósito de la no integración de la ciudad y la naturaleza/de la escisión entre ciudad y naturaleza cf. Gernot Böhme, Die Mensch-Natur-Beziehung am Beispiel der Stadt, en: Für eine ökologische Naturästhetik, Francfort sur le Main 1989, pp. 56-76: 70 y s.

${ }^{15}$ Gilles Clément, Le jardin en mouvement. De la Vallée au Parc André-Citroën, Sens \& Tonka 1994, p. 58.

${ }^{16}$ Michael Jakob, Ermenonville, Paris 2002

${ }^{17}$ La gran pirámide que se erige en medio del lago (Seepyramide) en el parque de Branitz alberga los restos mortales del príncipe Pückler y de su esposa, Louise.

18 Derek Jarman, Derek Jarman's Garden, Londres 1995

${ }^{19} \mathrm{Cf}$. Eric Hobsbawn, The Invention of tradition, Cambridge 1983.

${ }^{20}$ «Su tiempo [el tiempo del paisaje] es presentado en los anuncios como "good time": "What's your idea of a good time? - If you enjoy picknicking on a moutaintop, exploring quiet sideroads to picturesque fishing villages, strolling among scenes of colonial history or just dreaming under an apple tree". La "vista" que, estéticamente, constituye el paisaje puede aparecer, por ejemplo, bajo la forma que a continuación se describe: "Highways bring the finest landscape within easy reach of your camera" » (Joachim Ritter, Zwei Exkurse (zu: Landschaft), en: Metaphysik und Politik, Francfort sur le Main 2003, p. 437 [existe traducción al castellano incluida en Subjetividad: seis ensayos, Barcelona, Alfa, 1986, pp. 125 y ss.]).

${ }^{21}$ Cf. a propósito de esta otra faceta del paisaje: John Barrell, The dark side of the landscape, Cambridge 1980, Ann Bermingham, Landscape and ideology: The English rustic tradition 1740-1860, Berkeley 1986; Landscape and power (ed: W. J. T. Mitchell), Chicago 2002, extracto, pp. 5-34 (the Imperial Landscape).

22 Cf. Michael Jakob, Vandœuvres Paysage, Gollion 2003.

23 «spread of a new kind of landscape, based less on territoriality and 
specialized spaces with restricted access, and more on that vernacular liking for mobility and the temporary use of public or semi-public spaces. [...] One of its characteristics [of the commercial strip] was accessibility; another was the new style exterior of the buildings: gaudy, unconventional, and obviously designed to attract the mobile consumer and lure him into stopping. The strip was merely the earliest example of a kind of architecture meant to be experienced from the outside and to appeal to the passing motorist: We soon invented the drivein-bank, the drive-in-movie theater, and the drive-in church. Then there was the super truck stop, the supermotel, the supermarket, and (what is still evolving) the super service center for automobiles - an elaborately planned landscape containing every possible auto-oriented business, from tire repair to paint jobs to auto sales.» John Brinckerhoff Jackson, The Future of the Vernacular, en: Understanding ordinary landscapes (ed.: P. Groth, T. W. Bressi), New Haven/ 1997, pp. 145-156:151.

24 «What are the visible testaments to the American mercantile creed - the hamburger stand, gas station, diner, the ubiquitous billboards, sagging wires, the parking lot, car cemetery and that most complete conjunction of land rapacity and human disillusion, the subdivision. It is all but impossible to avoid the highway out of town, for here, arrayed in all its glory, is the quintessence of vulgarity, bedecked to give the maximum to the least of our accomplishments» (lan L. McHarg, Design with nature, New York 1992 [primera edición 1967], p. 20.)

25 «The space-time feeling of our period can seldom be felt so keenly as when driving, the wheel under one's hands, up and down hills, beneath overpasses, up ramps, and over giant bridges» Siegfried Giedion, Space, Time and Architecture: The Growth of a new Tradition, Cambridge/Mass. 1967, p. 831.

26 «The drive was a revealing experience. The road and much of the landscape was artificial, and yet il couldn't be called a work of art. On the other hand, it did something for me that art has never done. At first, I didn't know what it was, but its effect was to liberate me from many of the ideas I had about art. It seemed that there has been a reality there that had not had any expression in art. The experience of the road was something mapped out but not socially recognized» (Tony Smith, Talking with Tony Smith, en: Artforum 5, diciembre 1966 , p. 19)

27 Marc Desportes, Paysages en mouvement, Paris 2005, p. 339.

28 «Automobile culture contributes to the destruction of the natural environment and rural countryside. In bucolic landscapes, automobile tourism stimulates the construction of motels, service stations, vista points, and amusements that elongate and muddy the once tight urban edge. Places like the red canyons of Sedona, Arizona, deteriorate in the wake of development, the views of rock spires cluttered with signs for Happy Meals. [...] Even more insidiously, the subdivisions that surround most North American cities, because of their uniformity, their large planes of colour and texture, confront the automobile viewer with an architectural equivalent of the wilderness - the absence of any landmarks that might aid geographic comprehension and artistic contrast. Fields of corn follow fields of grey slate roofs. Hillsides of chaparral alternate with hillsides of red tile roo$\mathrm{fs}$. At each bend in the road, with each additional mile, we suffer the monotony of sameness. Driver and passenger glide adrift in the suburban sea» (Mitchell Schwarzer, Zoomscape. Architecture in Motion and Media, Princeton 2004, pp. 83-84)

29 Cf. al respecto de las torresmirador de Harlem, etc. Dean Maccannell, The Tourist. A New Theory of the Leisure Class, University of California Press 1999: "The New York Times reports that seventy people answered an advertisement inviting tourists to spend '21 days in the lands of the Hatfields and McCoy's for $\$ 380.00$, living in with some of the poorest people in the U.S. in Mingo County, West Virginia'. Similarly, in 1967, the Penny Sightseeing Company inaugurated extensive guided tours of Harlem. Recent ecological awareness has given rise to some imaginative variations: bus tours of 'The Ten Top Polluters in action' were available in Philadelphia during 'Earth Week' in April 1970» (40).

${ }^{30}$ Theodor W. Adorno, Fortschritt, en: Stichworte. Kritische Modelle 2, Francfort sur le Main 1969, pp. 29-56 : 46.

31 Cf. Albrecht Koschorke, Die Geschichte des Horizonts. Grenze und Grenzüberschreitung in literarischen Landschaftsbildern, Francfort sur le Main 1990, extracto. Die Öffnung des Horizonts, pp. 49-75: 77. Véase también Michel Collot, L'Horizon fabuleux, 2 vol., Paris 1988; La Poésie moderne et la structure d'horizon, Paris 1989.

${ }^{32}$ Natalie Böhler, Die Landschaft als Regisseurin, en: Cinema 47, Landschaften, Zurich 2002, pp. 62-72: 65. 


\section{Texto orixinal}

\section{Contre l'utopie temporelle: la temporalité du paysage}

Michael Jakob

Haute École du Paysage, d'Ingénierie et d'Architecture de Genève

Si le fait de parler d'une 'genèse' ou d'une 'invention' du paysage s'avère légitime, alors celle-ci a nécessairement lieu dans le temps'. II y a donc des temps, des époques avec et d'autres sans paysage. ${ }^{2}$ Les époques de paysage sont elles mêmes des entités temporelles : elles ont un début et une fin, des phases d'évolution, des mouvements ascendants et descendants. Autrement dit, le paysage a son histoire, il est l'histoire de la conscience du paysage, et l'expérience individuelle du paysage en tant qu'expérience esthétique vécue ne peut avoir lieu qu'à l'intérieur de ce cadre temporel. Le sujet qui constitue un paysage n'est pas seulement un corps qui se meut dans l'espace; il est aussi une conscience pénétrée d'histoire. Là où il y a paysage, il y a aussi rencontre de la nature et de l'histoire: I'histoire s'inscrit dans la nature.

Qu'en est-il cependant du rapport entre la plénitude temporelle de l'expérience esthétique dans sa singularité individuelle et l'apport de l'histoire sédimentée dans la conscience? Les expériences individuelles passent-elles à travers le filtre d'expériences collectives?

Au sens strict, la nature qui nous attire, pour être constituée en paysage, ne peut jamais être déterminée a priori. On ne peut la décrire ou la classifier qu'a posteriori, et c'est seulement à la lumière de cette détermination ultérieure qu'elle apparaîtra comme affectée par l'histoire, c'est-à-dire par des facteurs temporels. II s'agit donc de l'entreprise difficile de jeter un pont entre la subjectivité pure, absolue de l'expérience du paysage et des motifs intersubjectifs, des critères historiques de plaisir au paysage. ${ }^{3}$

L'expérience du paysage révèle cependant des caractéristiques diachroniques distinctes : selon les époques les hommes constitueront des images différentes de la nature. Les débuts sont ceux du beau paysage. L'expérience du paysage ne survient initialement que là où l'imagination reconnaît dans la nature des formes évoquant l'idée de bien-être, de sécurité et d'harmonie. ${ }^{4}$ Se sentir interpellé par la nature-jardin signifie avoir déjà intériorisé le processus culturel de domestication, le long 'travail' sur la nature préalable à toute constitution du paysage.

Cette première époque de la conscience du paysage révèle des ambiguïtés significatives sur le plan temporel. Elle postule en effet un idéal que représentent la littérature, la peinture (l'Âge d'or) et les jardins (avec leur programme intemporel de type néoplatonicien), tout en le déconstruisant déjà.

\section{Et in Arcadia ego}

L'irruption de la ruine dans le paysage marque à cet égard une première faille importante au sein de l'idéal. Les fragments du passé pointent dans le paysage bien avant la Renaissance. Des fresques antiques à Lorenzetti, de Patinir à Giorgione et Mantegna, sans oublier leur fonction essentielle dans le Songe de Polyphile, les ruines s'imposent partout. La ruine et la mort habitent le beau paysage, marquent dans celui-ci l'antithèse même de la pérennité, la vanité des choses de ce monde. En tant qu'indicateurs d'une absence, d'un manque fondamental, les ruines brisent les rêves dorés de la nature pacifiée à tout jamais. Le paysage est constitution, construction subjective de la part d'un sujet qui contrôle la nature soumise à son regard. L'omniprésence des ruines dans le paysage - à partir de 1530 aussi des ruines artificielles dans les jardins (Pesaro), jusqu'au paysage-ruine de Bomarzo souligne toutefois la revanche de la nature, l'instabilité et la qualité éphémère de l'appropriation du 
monde. ${ }^{5}$ Enfin, la mort faisant son entrée en Arcadie montre définitivement la fragilité et l'inanité du rêve de l'Âge d'or. Les tableaux du Guerchin et de Poussin (Et in Arcadia ego) expriment avec beaucoup de force cette différence temporelle, l'écart infini entre la nature paradisiaque et l'être fini face à l'allégorie du crâne ou du tombeau. ${ }^{6}$ Confronté à la finitude, le sens même des grands jardins de la Renaissance et de l'âge baroque se trouve comme ébranlé. La fête dans le domaine assume dès lors une importance particulière. Ainsi l'autre histoire du beau paysage est-elle liée à l'esthétique de l'éphémère : c'est l'histoire des féeries princières de l'Italie d'abord, de la France et de l'Europe toute entière plus tard. Les fêtes de Ferrare et Milan, les festivités toscanes (avec pour effet secondaire la naissance de l'opéra), le grand jour funeste de Vaux-le-Vicomte ou les Plaisirs de l'île enchantée de Versailles forment les pièces distinctes d'une suite de moments paysagers exemplaires. ${ }^{7}$

La première époque de la belle nature ou de la nature-jardin et de ses symétries formelles se termine avec l'entrée en scène révolutionnaire du jardin pittoresque (ou irrégulier, à l'anglaise, anglo-chinois8). La logique temporelle de ces nouvelles réalisations - et, de façon analogue, de la lecture des paysages en général - est de toute autre nature. L'ensemble de ces domaines tient compte du temps individuel du promeneur, du marcheur mélancolique qui devra se 'perdre' dans les méandres et les fourvoiements. Le sujet n'est désormais plus le subalterne passif soumis à une structure absolutiste qui fixe à tout jamais la place de tout et de chacun; il compose plutôt en cheminant son propre domaine et se compose de ce fait soi-même. La connaissance-constitution du jardin devient un événement singulier, une date individuelle. C'est à ce moment que la ruine, memento mori et métonymie de l'antiquité dans les jardins précédents, et surtout, la fausse ruine trouveront leur place au centre des compositions paysagères. La Colonne du Désert de Retz ou le Temple de la Philosophie d'Ermenonville fonctionnent à cet égard au milieu d'un dispositif sémiotique de grande complexité comme des phares, des symboles architecturaux de la différence temporelle. Tout porte dès lors dans ces compositions paysagères apparemment naturelles l'empreinte de la discontinuité : le promeneur s'arrête dans des ermitages et autres 'déserts' solennels interrompant son parcours et méditant la fausse grandeur des civilisations; I'histoire, la continuité, le programme - tout se fragmente et la mélancolie s'installe ; le futur même apparaît brisé, état qu'anticipe si bien l'un des protagonistes de la nouvelle esthétique pittoresque, Hubert Robert, dans sa vision du Louvre en ruine; les domaines enfin se meurent avec la Révolution, se transformant dans les ruines de leurs aspirations paradoxales.

Avant la scission de la Grande Révolution, c'est-à-dire aussi longtemps que la réception de ces domaines à la lumière de la liberté était assurée et pédagogiquement accompagnée, un élément statique y survivent quand même: on attendait en effet de la part des promeneurs, comme l'explique bien le marquis de Girardin dans sa théorie de la composition du paysage, de reconnaître des modèles picturaux traduits sur le terrain par l'auteur-paysagiste. ${ }^{9}$ L'activité authentiquement constructive et constitutive est donc placée à l'intérieur du sujet, là où souvenir et imagination continuent ce qui, dans la situation ponctuelle, n'était qu'impulsion. Celui qui regardait des parcs de ce genre apercevait en fin de compte moins la nature reconnue ou considérée comme telle que sa propre histoire, son être-devenu en tant qu'individu marqué par l'histoire. Le concept de finitude même se confond de ce fait dans l'infini d'une intériorité toute puissante:

Si le jardin pittoresque que l'on ferait peut-être mieux d'appeler jardin de la sensibilité, a tant aimé les ruines et les tombes, c'est qu'elles figuraient aux yeux du promeneur une image de la vie même de la pensée humaine. Elles donnaient aux âmes sensibles la douleur de les percevoir et la consolation de voir la nature y conserver une image de notre pensée. Une douleur apaisée générant un plaisir, elles mettaient le promeneur dans un état instable et délicieux où ses états d'âme, sans cesse, pouvaient se moduler en leur contraire. ${ }^{10}$

\section{Paysage au-délà du beau}

A la grande phase historique de la nature belle, pittoresque et sublime, source de l'expérience du paysage, succède l'époque que l'on pourrait définir celle du 'paysage au-délà du beau', qui - comme les autres courants, il est vrai - s'étend jusqu'à notre époque. Le laid, le fragmentaire, l'imparfait, le 
dégoûtant même pénètrent désormais le champ visuel et avec eux d'autres formes de temporalité. Autour de 1860-70 le goût pour le 'non-beau' est devenu un phénomène marquant : " J'adore la banlieue avec ses champs en friche/ Et ses vieux murs lépreux, où quelque ancienne affiche/ Me parle de quartiers dès longtemps démolis ", lit-on dans Promenades et Intérieurs de François Coppée."

L'architecture du paysage contemporaine a beaucoup de rapports avec cet imaginaire du 'nonbeau', celui de la ville blessée et bétonnée, de la città diffusa, du no man's land, des slums, des friches agricoles, industrielles ou urbaines et des décharges. Cette centralité surprenante des marges, de la périphérie, est le résultat d'une tendance qui s'étend sur plusieurs décennies et a son origine, entre autre, dans le land art, dans les travaux photographiques des 'new topographers' (exposition New Topographics, New York 1975), mais aussi dans l'esthétique cinématographique (Antonioni, Tarkovski). La beauté étrange de ce nouveau paysage technologique marqué de fond en comble par l'intervention humaine nous confronte avec des situations paradoxales. Ce paysage est à la fois celui du vide et du trop plein, de l'absence et de la saturation. II est aussi fascinant qu'angoissant, voir répugnant et culmine dans différentes formes d'assemblage proches de l'état de déchet. ${ }^{12}$

Il s'agit d'un paysage sans confins précis, diffus, qui exhibe partout les stigmates de la non-assimilation de ses composantes, les traces mélancoliques de l'inachevé. C'est vers ce genre de paysage autre au-delà de toutes les esthétiques du pittoresque que l'architecture du paysage de la fin du XX siècle s'est tournée avec force, comme l'indique bien Dieter Kienast:

Notre travail est la recherche d'une nature de ville dont la couleur ne soit pas seulement le vert, mais aussi le gris. Nature de ville, cela veut dire arbre, haie, gazon, mais aussi revêtement de sol qui laisse passer l'eau, vaste place, canal rigoureux, haut mur, axe d'air frais ou de vue laissé libre, le centre et le bord. Notre attention particulière se porte sur les innombrables non-lieux nés de la planification et de l'aménagement bureaucratiques. Des actions d'urbanisme, incluant aussi l'architecture du paysage, nous apparaissent d'une importance essentielle justement pour la périphérie, pour les restes d'espace indésirables de la métropole. ${ }^{13}$

Malgré cet intérêt croissant pour la périphérie, la nature résiduelle et l'anti-nature, la nature pure (ou mieux : le simulacre d'une nature 'pure' ou bien 'vraie') se porte toujours bien. Cette nature survit, surtout sous son aspect muséal. Elle est recherchée et adulée par le public contemporain - la nature des vacances et des loisirs, la nature proche et lointaine, celle des plages, des cimes alpines et des déserts, c'est-à-dire la nature infiniment reproduite et fabriquée de toute pièce par le discours paysager global.

II en va tout autrement de l'architecture du paysage contemporaine de pointe: celle-ci semble avoir laissé derrière-elle l'esthétique des jardins, le culte de la belle nature, pour privilégier tout ce qui a trait à l'urbain, voir à l'hyper-urbain. L'architecture du paysage récente inscrit de ce fait dans ses projets les signes ambigus de notre époque, à savoir le sens de dislocation et de fragmentarité. ${ }^{14}$

Qu'est-ce qui caractérise en effet le style d'un Dieter Kienast sinon la volonté d'imposer résolument, obstinément, un geste architectonique antithétique, dérangeant ? La réduction extrême des moyens utilisés et la mise en scène d'éléments formels à la Gestalt caractéristique distingue les œuvres de Kienast du standard banal et répétitif des réalisations habituelles. Kienast rompt donc aussi bien avec la tradition idyllique ou romantique, qu'avec une pratique de l'aménagement des jardins qui privilégie la variété pour la variété et l'abondance des plantes (la rage du collectionnisme). L'opposition forte entre l'énergie du végétal et la discipline formelle des géométries inventées ainsi que la création d'une spatialité inhabituelle (et non point de gags en corten ou autres provocations faciles), exige de la part de celui qui pénètre ces espaces une lecture active du site, bref : elle exige toujours le temps de la découverte.

D'autres de leur côté essaient, comme Gilles Clément, de restituer leurs compositions à la nature, laissent le temps de la nature reprendre le dessus. Chez Clément, la négation résolue de l'ordre immuable au profit du désordre créatif a son origine dans la conviction que, sur la planète Terre, I'homme voit le temps lui filer entre les doigts. La perspective écologique prônée par le théoricien du " jardin planétaire » a pour effet d'exposer la réalisation aux hasards et accidents de la nature. Alors que l'art des jardins, traditionnellement, mise tout sur la domination du temps - de façon particuliè- 
rement éclatante dans le jardin raisonné de type français avec son contrôle absolu de la croissance, de la forme, du chromatisme, des saisons etc. -, Clément remet la nature à la nature. La liberté inattendue de ses projets s'inspire aussi bien des 'jardins involontaires' rencontrés dans les friches du monde entier que du spectacle du 'brassage' des espèces (notamment des vagabondes) donnant lieu à de nouveaux paysages. Cette liberté retrouvée nous fait participer au temps de par la rencontre permanente avec des éléments inattendus, de par l'esthétique du 'décalage' cultivée par Clément:

Les décalages sont des phénomènes mineurs et essentiels. Ils agissent comme des catalyseurs, déclenchent des réactions imprévues, introduisent dans le paysage des dimensions singulières hors du contexte qui les a fait naître, parfois intimes parce que subjectives. L'intérêt des décalages est de relancer la dynamique de l'observation. ${ }^{15}$

A cette esthétique du 'décalage' telle qu'elle se montre dans les projets de Gilles Clément on peut ajouter - en tant que pratique également consciente du temps - l'esthétique de Derek Jarman. Le jardin de l'artiste anglais, à Dungeness dans le Kent, est une œuvre 'terminale'. Atteint par la mort imminente, Jarman invente un lieu de liberté dans un milieu austère et étrange. De par sa création même cet anti-jardin pose la question du temps : pour qui ? - pour combien de temps ? - en combien de temps ? aménage-t-on un site ? Et que deviendra-t-il au moment de la mort, cette mort qui est l'invitée non voulue de l'histoire des jardins, la mort de Julie et de son 'Elysée' chez Rousseau, la mort de Charlotte et de Otto dans les Affinités électives, ou, plus concrètement, la mort des parcs et des féeries paysagères au moment de la Révolution, exprimée par exemple dans la Sylvie de Nerval. ${ }^{16}$ Vivre et disparaître dans son jardin est cependant aussi le destin final du prince Pückler enfermé à tout jamais à la fin de sa vie dans sa pyramide, monument réel de sa présence au moment même de sa dissolution. ${ }^{17}$

Le jardin de Dungeness est marqué par la finitude, la mortalité de l'existence humaine, une situation qui délivre cependant son auteur, pour lequel cet espace devient un dernier remède puissant et thérapeutique (dans la tradition du jardin médicinal).

L'adieu paysager de Jarman se révèle être malgré sa simplicité apparente et sa spontanéité d'une extrême complexité. Le cottage avec sa végétation spontanée et ses objets trouvés fonctionne comme un véritable domaine de la mémoire culturelle. Les morceaux de bois et autres fragments verticaux fixés dans la terre rappellent l'acte primordial du contrôle du territoire, le pieux enfoncé dans le sol ou bien la pierre milliaire. L'anthropologie de l'homo erectus apparaît dès lors dans ce waste land aux tonalités particulières sous deux aspects : celui, plein d'énergie, de l'élan vers le ciel, de la verticale victorieuse, et celui, mélancolique et friedrichien d'une élévation à temps, de portée limité.

En proximité immédiate d'une centrale nucléaire - avec tout ce que la réalité et l'image de cette énergie comporte - le jardin sec et minéral prend la forme d'un geste final et désespéré dans la suite du Moine à la mer de Caspar David Friedrich. L'ouverture du ciel immense, le jeu et la résistance inouïes de la végétation identifient cependant dans ce désordre poétique la force de la vie elle-même. La beauté éphémère des coquelicots qui se dégage sur le fonds de la blancheur du jardin sec aux allures orientales exprime elle aussi la vie, les durées complexes et multiples du vivant.

Jarman a crée comme dernière œuvre un espace aux innombrables citations plus ou moins involontaires : le concept de ready made, la technique du collage et de l'assemblage de Schwitters, la poésie des machines de Tinguely, les objets en pierre composés par Richard Long, ou bien encore les visions d'un Yves Tanguy trouvent ici un reflet étonnant. Tout est signifiant a Dungeness, mais rien n'est expliqué, ce qui demande de la part du visiteur une attention accrue ${ }^{18}$. Avec ce jardin de la réduction et de la disparition, où même la rouille apparaît pleine de vigueur, Jarman a réussi de faire revivre une réalité et un dispositif paysager puissant d'autrefois : celui du jardin pittoresque (ou anglais) qui, en tant qu'objet d'art conçu pour un promeneur sensible, provoquait l'éveil du sujet et notamment la prise de conscience de la temporalité au cœur de la subjectivité même.

Que ce soit chez Kienast, Clément, ou Jarman - toutes ces œuvres ont en commun la fragmentarité et l'acceptation des effets du temps. 


\section{Autopia}

Si là où il convainc, I'architecte du paysage d'aujourd'hui inscrit dans son esquisse la différence de temps, l'industrie de l'image (de la publicité, du voyage) se cramponne, quant à elle, au temps nivelé. Son idéal, c'est la persistance d'un paysage de carte postale qui plaît en tant que spectacle éternel. ${ }^{19}$ A bien y regarder, la plupart de ces paysages ne se révèlent pas seulement hautement anthropomorphes, mais aussi liés à l'image glorifiée de l'exploitation agricole. Le paysage modelé par l'agriculture devient paysage idéal là où cette activité est regardée de l'extérieur (par le touriste), là où elle est en crise (la longue mort de la paysannerie face à la mécanisation) ou bien là où, historiquement déjà dépassée, elle s'embellit des nostalgies de la terre natale. Ce paysage reflète alors le «bon vieux temps», "the good time» ${ }^{20}$, un temps qui cependant n'a jamais vraiment existé. ${ }^{21}$

Le culte du rural et de l'archaïque remplace, confronté à la mort de la ruralité préindustrielle, la réflexion, la confrontation avec le corps agonisant de l'agriculture. Ce genre de sacralisation conduit forcément à des solutions douteuses, comme celle d'ériger les derniers paysans en 'gardiens du paysage'. ${ }^{22}$ La simultanéité de ces deux esthétiques a pour conséquence une situation polaire proche de la schizophrénie: nous sommes aujourd'hui à la fois le spectateur ou citadin avide de nature, celui qui estime que tout doit absolument rester comme autrefois, que l'on décrète l'arrêt total de la construction, et ailleurs, et même tout près, nous participons de plein gré à la temporalité galopante de la modernité post-industrielle. Nous encourageons la sauvegarde des icônes paysagères, la stase et la vitrine, tout en promouvant la force qui a marqué de son empreinte non seulement les rêves (et les cauchemars) futuristes, mais le monde du XXe siècle tout court: la vitesse. John B. Jackson a été parmi les premiers à souligner l'impact de la vision automobile sur la vie et sur le paysage contemporain. Jackson parle de la

propagation d'un nouveau type de paysage, moins basé sur la territorialité et sur des espaces caractéristiques à l'accès limité, et plus sur le goût vernaculaire de la mobilité et l'utilisation temporaire d'espaces publiques ou semi-publiques [...] L'une de ses caractéristiques était l'accessibilité, l'autre le nouveau style extérieur des bâtiments : gai, non conventionnel, et clairement conçu pour attirer le consommateur mobile en le forçant à s'arrêter. Le 'strip' était l'un des exemples les plus précoces d'un genre d'architecture à expérimenter de l'extérieur et qui puisse être prisé par le conducteur en train de passer. C'est ainsi que nous avons inventé la drive-in-bank, le cinéma drive-in, de même que l'église drive-in. Il y eut aussi le parking géant pour les camionneurs, le supermotel et le supermarché, et encore le supergarage au service des automobilistes un paysage élaboré sur mesure qui contenait tous les business concernant la voiture : changement de pneus, vernissage de la carrosserie ou vente d'autos. ${ }^{23}$

A la neutralité de cette description d'un paysage marqué par le trafic et le temps accéléré on peut opposer un passage polémique dans Design with nature de lan McHarg:

Quels sont les lais visibles du credo mercantile américain ? Le stand aux hamburgers, la station de service, le resto-route, les omniprésents panneaux publicitaires, les fils électriques qui pendouillent, les emplacements de parking, les casses et les lotissements, ces symbioses totales entre rapacité territoriale et humaine désillusion. A l'extérieur de la ville, il est absolument impossible d'échapper aux autoroutes, puisque c'est là que nous attend, auréolée de toute sa gloire, la quintessence de la vulgarité, crée pour donner le maximum de poids à la moins importante de nos réalisations. ${ }^{24}$

Ce n'est pas seulement aux Etats-Unis, mais dans le monde entier que les infrastructures liées aux transports sont les véritables artères d'un système qui envahit l'ensemble du territoire. Le paysage urbain, les voies de la ville vers l'extérieur, les villages qui n'en sont plus, les lieux de vacances en tant que simulacres de la forme urbaine ont été conçus pour l'automobiliste qui les appréhende en roulant. Au plus tard après la deuxième guerre mondiale «autopia» ( $R$. Banham) a gagné, elle s'est imposée sur le plan culturel, social et économique.

Modernité et automobilité ont été longtemps synonymes. «Le sentiment espace-temps de notre époque on le ressent au mieux en conduisant un véhicule alors que les mains sont posées sur le volant et que l'on passe par vaux et par monts, que l'on emprunte des viaducs, au-dessus des rampes 
et des ponts gigantesques. $\$^{25}$ L'automobile n'a pas uniquement créé de nouvelles formes paysagères (streetscapes), mais également une nouvelle manière d'appréhender la réalité26:

Le panorama autoroutier est l'épreuve de ce don au cours duquel le paysage vient au-devant de la personne et la submerge. II y a à la fois détachement du cadre spatial immédiat et sensation d'une proximité visuelle, ou plutôt écrasement visuel, ce terme se référant à la suppression de la profondeur de champ qu'opèrent la photographie et le cinéma. Le sujet voit s'ouvrir à lui l'espace, le reçoit, acquiert une position de pur spectateur. ${ }^{27}$

L'automobile reproduit les contradictions de la mobilité (une caractéristique fondamentale de la modernité) : elle génère de nouvelles topographies et de nouvelles possibilités esthétiques d'explorer la réalité, mais détruit en même temps le charme de la réalité à laquelle elle donne un accès facilité:

La culture de l'automobile contribue à la destruction de l'environnement naturel et du paysage rural. Le tourisme automobile pousse à la construction de motels, stations de service, vista points et divertissements de tout genre qui prolongent et désagrègent les angles urbains autrefois si bien définis. Endroits tels les canyons rouges de Sedona dans l'Arizona sont détruits par le progrès, et le panorama des rochers en cascade est fragmenté par les écritaux de Happy Meals. [...] de façon d'autant plus insidieuse, les lotissements tout autour de la plupart des villes nord-américaines, à cause de leur uniformité, de leurs larges plaines colorées, mettent le conducteur automobile en face d'un équivalent architectural des grandes espaces sauvages - tout repère aidant à comprendre la géographie du lieu et le contexte esthétique en est absent. Des champs uniformes de maïs suivent des champs de toits gris. Des collines de maquis s'alternent avec des collines de toits rouges. A chaque virage, avec chaque kilomètre additionnel, nous souffrons de la monotonie de la mêmeté. Conducteur et passager glissent directement dans la mer suburbaine. ${ }^{28}$

\section{Time Landscape}

L'illusion autopique qui a modelé les paysages de l'après-guerre se place, du point de vue temporel, sous le signe de l'avance inexorable, de l'élan vers l'avenir, et ceci du fait que l'on ne regarde jamais en arrière, mais, frontalement, toujours en avant. Plus nous avons étendu la sphère autopique, plus nous avons cependant réduit les espaces à atteindre. Le résultat est, sur le plan de l'imaginaire territorial, la simultanéité paradoxale du «sprawl» urbain, de la genèse rapide d'un espace interstitiel illimité à l'enseigne de la technologie, l'omniprésence de la machine, et la survie de bouts de nature soustraits au progrès sous la forme d'enclaves résiduelles.

La tendance actuelle de l'architecture, de l'urbanisme, mais aussi des sciences humaines, bref, de la culture en général, à se tourner résolument vers la périphérie, vers les sites interstitiels et vers les métastases territoriales représente un phénomène paysager important, et ici aussi le facteur temps apparaît particulièrement pertinent. Champs en jachère, districts industriels fragiles, tristes faubourgs et entre-deux contaminés sont aujourd'hui des objets fascinants. Si autrefois la photographie de mode choisissait pour cadre des châteaux, des villas, des sommets ou des plages exotiques, aujourd'hui les modèles doivent souvent exhiber leurs vêtements coûteux dans des décharges ou usines abandonnées, au milieu de paysages hybrides à l'opposé de l'esthétique du beau. Le cinéma et la publicité ont encore renforcé cette tendance et bientôt, si ce n'est pas déjà fait, I'industrie touristique proposera des tours organisés dans les bidonvilles, des voyages dans les faubourgs de Beyrouth, Sarajevo ou Bagdad, des bed and breakfast pas comme les autres. ${ }^{29} \mathrm{Ce}$ penchant à rechercher, voire à célébrer le laid, I'hybride et le périphérique est aussi l'expression de l'échec ou de la fin de la croyance au progrès. C'est tout à fait comme si «la contradiction avait [réveillé] l'esprit dans sa propre évolution et qu'elle essaie, en vain il est vrai, de le corriger de son erreur par le recours à ce dont il s'est distancié et que pour cela il croit à tort invariant. »30 La perspective tournée vers le futur, en avant - le paysage comme horizon et ouverture : "A I'horizon ouvert de l'expérience de l'espace correspond un horizon de I'histoire ouvert sur l'avenir, c'est-à-dire permettant à l'homme de modeler librement»»31 fait désormais place à des scènes entropiques.

Robert Smithson l'avait déjà bien reconnu dans les années '60 en portant son attention sur le paysage pollué, détruit, menacé. Dans ses œuvres le vecteur du futur, déjà déstabilisé dans les 
visions figées de Caspar David Friedrich, se trouve complètement inversé. L'évolution - la spirale - va en arrière (Spiral Hill, Emmen), le temps se rétrécit, disparaît inexorablement, comme la Spiral Jetty (1970), icône d'une époque sous le signe de l'entropie (le 'retour à la nature' correspond chez Smithson à une esthétique de la disparition). Que ce geste de l'artiste américain touche en général notre conscience du temps et de l'histoire, mais aussi l'esthétique passéiste du paysage, c'est ce que fait voir un tableau hautement ironique de Mark Tansey (Purity Test, 1982) où un groupe d'Indiens à cheval semble jeter un dernier regard admiratif à la Spiral Jetty, produit final de la conscience européenne du paysage et en même temps négation de celle-ci. Cette vision paradoxale déconstruit les grands mythes historiques (le discours d'époques, de seuils, de changements de paradigmes etc.) et dévoile les contradictions d'un point de vue qui, en tant que construction culturelle, reflète toujours des ambiguïtés temporelles.

Les artistes que l'on range aujourd'hui dans le Land Art ont toujours privilégié le phénomène temps. Time Line et Time Pocket (1968) de Dennis Oppenheim explorent les lignes internationales du temps au moyen de mouvements qui s'inscrivent de manière éphémère (les traces de vingt-cinq $\mathrm{cm}$ de large du scooter des neiges) dans l'éphémère (la Saint-John-River glacée et enneigée). Le temps abstrait, normé se trouve ainsi 'déjanté', la convention temporelle (les zones de temps) abolie, mais, typiquement, de ce geste il ne reste qu'une trace photographique. Annual Rings (1968) du même artiste associe la mesure temporelle de la nature (les anneaux des arbres) au temps mesurable et normé qui se sépare de façon surprenante à la frontière horaire entre le Canada et les USA (USA 13 h30 - Canada 14h30). Tout comme Smithson ou Richard Long, Oppenheim confronte donc le processus artistique avec les conventions temporelles, ainsi qu'avec le moment de la réception des œuvres d'art. L'instant, l'action significative, limitée dans le temps, l'actualité sont ainsi opposés à l'éternité de l'art, à sa place assignée dans les salles des musées avec leurs monuments immobiles. La conscience du passage du temps n'est jamais refoulée ; c'est elle, au contraire, qui constitue la substance de travaux comme Spiral Jetty, One Hour Run d'Oppenheim (1968) ou A Walk of four hours and four circles de Richard Long (1972).

Une autre œuvre de la même période souligne elle aussi la complexité de l'expérience temporelle. Time Landscape (1978) d'Alan Sonfist reconstruit à Manhattan, au milieu de la forêt 'urbaine', la forêt vierge biologique d'avant l'arrivée de l'homme sur la presqu'île new-yorkaise, et ceci en proximité immédiate de la 'forêt' des gratte-ciel. La 'fenêtre' spatio-temporelle de Sonfist illumine aussi bien le passé lointain, pré-anthropomorphe, qu'un futur dans lequel Manhattan, monument de la civilisation par excellence, cédera peut-être à nouveau la place à la forêt primitive.

Le cinéma structural des années '70 interroge également l'aspect temps dans l'expérience paysagère. Dans Seven Days de Chris Welsby - l'hebdomade fait clairement allusion à une mesure importante dans notre façon de compter le temps et à la signification culturelle du chiffre sept - les sept jours de tournage sont ramassés en 19 minutes, l'image changeant toutes les 10 secondes. Le fait que la caméra suive le jour solaire, assigne au film un laps de temps et une bande temps qui apparaissent significatifs d'un point de vue anthropologique et territorial. Le regard technomorphe de Welsby rappelle le point de vue humain, mais aussi la pratique millénaire de l'observation du ciel. Ici, c'est précisément le mouvement machinal, régulier de la caméra qui fait apparaître la constitution humaine du visible, ainsi que ce qui, dans la nature ou en tant que nature, se soustrait à l'homme:

Deux images de même cadrage ne sont jamais rigoureusement semblables, il y a une infinité de variations. Les formes des nuages changent, comme leur transparence, leurs couleurs et celles du ciel, la lumière qui tombe sur le paysage, la surface du paysage. ${ }^{32}$ 


\section{NOTES}

${ }^{1}$ Este artículo recoge algunas ideas presentadas en el libro Paysage et temps (Lausanne 2007) inéditas en lengua castellana.

${ }^{2}$ «On a souvent constaté que le véritable 'sentiment de la nature' ne s'est développé que dans les temps modernes et on en a trouvé l'origine dans leur lyrisme, leur romantisme etc ; quelque peu superficiellement, à ce que je crois. Les religions des temps primitifs me paraissent manifester un sentiment particulièrement profond de la 'nature'. Seule la sensibilité à l'objet 'paysage' s'est éveillée tardivement, et cela justement parce que sa création demandait qu'on s'arrachât à ce sentiment unique et homogène de la nature universelle» (Georg Simmel, Philosophie der Landschaft, dans: Aufsätze und Abhandlungen 1909-1918, vol. 1, Francfort sur le Main 2002, pp. 471-482: 472-3). Cf . aussi Michael Jakob, L'émergence du paysage, Lausanne 2004; Piero Camporesi, Le belle contrade, Milano 1992. - W. J. T. Mitchell (Landscape and power, Chicago 2002) a qualifié cette chronologie de l'évolution du paysage de «pseudohistorical myth» et en a souligné l'ambivalence: «lt is almost as if there is something built into the grammar and logic of the landscape concept that requires the elaboration of a pseudohistory, complete with a prehistory, an originating moment that issues in progressive historical development and (often) a final decline and fall» ( $p$. 12). Sa remarque cependant équivaut seulement à une critique des «Western ideas» ou du «Western mind» (p. 13) sans proposer d'alternative. Même une autre histoire du paysage, une histoire de «woman, gatherer, scientist, poet, interpreter, or tourist» (p. 16) est soumise à des facteurs historiques

${ }^{3} \mathrm{Cf}$. Michael Jakob, L'émergence, op. cit.

${ }^{4}$ Cf. Jay Appleton, The expérience of landscape, Londres 1975.

${ }^{5} \mathrm{Cf}$. Thomas M. Greene, The Light in Troy: Imitation and Discovery in Renaissance Poetry, New Haven 1982; Hartmut Böhme, Ruinen - Landschaften. Zum Verhältnis von Naturgeschichte und Allegorie in den späten Filmen von Andrej Tarkowskij, dans : Natur und Subjekt, Francfort sur le Main 1988, pp. 334-379.

${ }^{6}$ Le premier paysage nommé ainsi, La Tempesta de Giorgione et les ruines. Les ruines aussi chez Patinir.

${ }^{7}$ Cf. pour le jardin baroque et l'éphémère Michael Jakob, Cos'è barocco nel giardino barocco?, dans: Horti Verbani. Coltura e cultura dei giardini verbanesi, Verbania 2001, pp. 97-109; Michel Baridon, Les Jardins de l'âge baroque et le style de Le Nôtre, dans: Les Jardins à la française de la Renaissance à nos jours, Les Dossiers de l'Art, n 89, pp. 28-51.

${ }^{8} \mathrm{Cf}$. John Dixon Hunt, The picturesque garden in Europe, Londres 2002.

${ }^{9}$ "L'objet essentiel est donc de commencer par bien composer le grand ensemble et les tableaux pour I'habitation de tous les côtés où se dirigent les principales vues [...] pour composer un paysage et le rapporter sur le terrain, le tableau est la seule manière d'écrire son idée pour s'en rendre un compte exact avant de l'exécuter.» René-Louis de Girardin, De la composition des paysages, Seyssel 1992, pp. 23, 29. Cf. tout le chap. VIII, pp. 67-68. Pope a déjà déclaré : "All gardening is landscape-painting. Just like a landscape hung up» (cité dans John Dixon Hunt (v. note 33 ), pp. 14-5 (on y trouve d'autres indications sur le rôle des tableaux.)

${ }^{10}$ Michel Baridon, Les mots, les images et la mémoire des jardins, dans: Le Jardin, art et lieu de mémoire (éd. : M. Mosser, Ph. Nys), Besançon 1995, pp. 183-206.

${ }^{11}$ François Coppée, Fuvres complètes: Poésies, tome I, Paris 1885, p. 317.

12 «We have gone from ruin to rust, from trace to waste.» (Antoine Picon, Anxious Landscapes: From the Ruin to Rust, dans: Grey Room 01, Fall 2000, p. 77).

13 Dieter Kienast, Die Poetik des Gartens. Über Chaos und Ordnung in der Landschaftsarchitektur, Bâle 2002, pp. 207-8.

${ }^{14}$ Pour la non-intégration de la ville et de la nature cf. Gernot Böhme, Die Mensch-Natur-Beziehung am Beispiel der Stadt, dans: Für eine ökologische Naturästhetik, Francfort sur le Main 1989, pp. 56-76: 70 et s.
${ }^{15}$ Gilles Clément, Le jardin en mouvement. De la Vallée au Parc André-Citroën, Sens \& Tonka 1994, p. 58.

${ }^{16}$ Michael Jakob, Ermenonville, Paris 2002 .

${ }^{17}$ La grande pyramide au milieu du lac (Seepyramide) dans le domaine de Branitz contient les dépouilles du Prince Pückler et de son épouse, Louise.

${ }^{18}$ Derek Jarman, Derek Jarman's Garden, Londres 1995.

${ }^{19} \mathrm{Cf}$. Eric Hobsbawn, The Invention of tradition, Cambridge 1983.

${ }^{20}$ «Son temps [celui du paysage] est présenté dans les annonces comme 'good time': 'What's your idea of a good time ? - If you enjoy picknicking on a moutaintop, exploring quiet side-roads to picturesque fishing villages, strolling among scenes of colonial history or just dreaming under an apple tree'. La 'vue' esthétiquement constitutive du paysage peut revenir par exemple sous cette forme: 'Highways bring the finest landscape within easy reach of your camera.' » (Joachim Ritter, Zwei Exkurse zu: Landschaft, dans: Metaphysik und Politik, Francfort sur le Main 2003, p. 437).

${ }^{21} \mathrm{Cf}$. à propos de cette autre facette du paysage : John Barrell, The dark side of the landscape, Cambridge 1980 ; Ann Bermingham, Landscape and ideology: The English rustic tradition 17401860, Berkeley 1986; Landscape and power (éd.: W. J. T. Mitchell), Chicago 2002, en part. pp. 5-34 (the Imperial Landscape).

${ }^{22}$ Cf. Michael Jakob, Vandœuvres Paysage, Gollion 2003.

${ }^{23}$ "spread of a new kind of landscape, based less on territorality and specialized spaces with restricted access, and more on that vernacular liking for mobility and the temporary use of public or semi-public spaces. [...] One of its characteristics [of the commercial strip] was accessibility; another was the new style exterior of the buildings : gaudy, unconventional, and obviously designed to attract the mobile consumer and lure him into stopping. The strip was merely the earliest example of a kind of architecture meant to be experienced from the outside and to appeal to the passing motorist: We soon invented the drivein-bank, the drive-in-movie theater, and the drive-in church. Then there was the 
super truck stop, the supermotel, the supermarket, and (what is still evolving) the super service center for automobiles - an elaborately planned landscape containing every possible auto-oriented business, from tire repair to paint jobs to auto sales.» John Brinckerhoff Jackson, The Future of the Vernacular, dans: Understanding ordinary landscapes (éd. : P. Groth, T. W. Bressi), New Haven/ Londres 1997, pp. 145-156:151.

${ }^{24}$ «What are the visible testaments to the American mercantile creed - the hamburger stand, gas station, diner, the ubiquitous billboards, sagging wires, the parking lot, car cemetery and that most complete conjunction of land rapacity and human disillusion, the subdivision. It is all but impossible to avoid the highway out of town, for here, arrayed in all its glory, is the quintessence of vulgarity, bedecked to give the maximum to the least of our accomplishments.» (Ian L. McHarg, Design with nature, New York 1992 [première édition 1967], p. 20.)

25 «The space-time feeling of our period can seldom be felt so keenly as when driving, the wheel under one's hands, up and down hills, beneath overpasses, up ramps, and over giant bridges.» Siegfried Giedion, Space, Time and Architecture : The Growth of a new Tradition, Cambridge/Mass. 1967, p. 831.

${ }^{26}$ «The drive was a revealing expérience. The road and much of the landscape was artificial, and yet il couldn't be called a work of art. On the other hand, it did something for me that art has never done. At first, I didn't know what it was, but its effect was to liberate me from many of the ideas I had about art. It seemed that there has been a reality there that had not had any expression in art. The experience of the road was something mapped out but not socially recognized.» (Tony Smith, Talking with Tony Smith, dans: Artforum 5, décembre 1966, p. 19)

27 Marc Desportes, Paysages en mouvement, Paris 2005, p. 339.

28 "Automobile culture contributes to the destruction of the natural environment and rural countryside. In bucolic landscapes, automobile tourism stimulates the construction of motels, service stations, vista points, and amusements that elongate and muddy the once tight urban edge. Places like the red canyons of Sedona, Arizona, deteriorate in the wake of development, the views of rock spires cluttered with signs for Happy Meals. [...] Even more insidiously, the subdivisions that surround most North American cities, because of their uniformity, their large planes of colour and texture, confront the automobile viewer with an architectural equivalent of the wilderness - the absence of any landmarks that might aid geographic comprehension and artistic contrast. Fields of corn follow fields of grey slate roofs. Hillsides of chaparral alternate with hillsides of red tile roofs. At each bend in the road, with each additional mile, we suffer the monotony of sameness. Driver and passenger glide adrift in the suburban sea.» (Mitchell Schwarzer, Zoomscape. Architecture in Motion and Media, Princeton 2004, pp.
83-84)

${ }^{29} \mathrm{Cf}$. pour les sightseeing tours à Harlem etc. Dean Maccannell, The Tourist. A New Theory of the Leisure Class, University of California Press 1999: "The New York Times reports that seventy people answered an advertisement inviting tourists to spend '21 days in the lands of the Hatfields and McCoy's for $\$ 380.00$, living in with some of the poorest people in the U.S. in Mingo County, West Virginia'. Similarly, in 1967, the Penny Sightseeing Company inaugurated extensive guided tours of Harlem. Recent ecological awareness has given rise to some imaginative variations : bus tours of 'The Ten Top Polluters in action' were available in Philadelphia during 'Earth Week' in April 1970.» (40)

${ }^{30}$ Theodor W. Adorno, Fortschritt, dans: Stichworte. Kritische Modelle 2, Francfort sur le Main 1969, pp. 29-56: 46.

31 Cf. Albrecht Koschorke, Die Geschichte des Horizonts. Grenze und Grenzüberschreitung in literarischen Landschaftsbildern, Francfort sur le Main 1990, en part. Die Öffnung des Horizonts, pp. 49-75 : 77. Voir aussi Michel Collot, L'Horizon fabuleux, 2 vol., Paris 1988 ; La Poésie moderne et la structure d'horizon, Paris 1989.

${ }^{32}$ Natalie Böhler, Die Landschaft als Regisseurin, dans: Cinema 47, Landschaften, Zurich 2002, pp. 62-72: 65. 